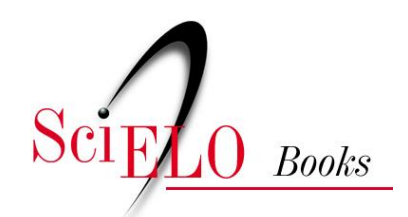

\title{
Comunicação pública digital em ciência e tecnologia
}

\author{
Henrianne Barbosa
}

\section{SciELO Books / SciELO Livros / SciELO Libros}

BARBOSA, H. Comunicação pública digital em ciência e tecnologia. In HAYASHI, MCPI., SOUSA, CM., and ROTHBERG, D., orgs. Apropriação social da ciência e da tecnologia: contribuições para uma agenda [online]. Campina Grande: EDUEPB, 2011. pp. 155-189. ISBN 978-85-7879-187-2. Available from SciELO Books <http://books.scielo.org>.

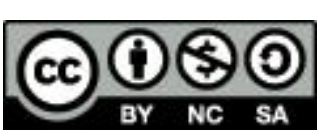

All the contents of this work, except where otherwise noted, is licensed under a Creative Commons Attribution-Non Commercial-ShareAlike 3.0 Unported.

Todo o conteúdo deste trabalho, exceto quando houver ressalva, é publicado sob a licença Creative Commons Atribuição Uso Não Comercial - Partilha nos Mesmos Termos 3.0 Não adaptada.

Todo el contenido de esta obra, excepto donde se indique lo contrario, está bajo licencia de la licencia Creative Commons Reconocimento-NoComercial-CompartirIgual 3.0 Unported. 


\section{Comunicação Pública Digital em Ciência e Tecnologia}

Henrianne Barbosa

\section{Introdução}

A apropriação social de C\&T exige tanto a aquisição de informação quanto a inserção do público em debates e decisões. Entende-se que a informação isolada se caracteriza pela verticalidade, subordinação, imperatividade, ordens e propaganda (PASQUALI, 2005, p.27). Em contraposição, as ações comunicativas favorecem a construção conjunta de saberes, a "mensagem/diálogo", identificada pela reciprocidade e decisões compartilhadas (Id.). Com a Internet, tem-se potencialmente a interação, na convergência não apenas de diferentes meios de comunicação, com dispositivos multimídia, mas na confluência de ideias díspares, de cidadania interconectada. 
Pelo viés tecnológico, é possível interagir. Mas persistem assimetrias, no que se refere, por exemplo, ao acesso à tecnologia, às regulações legais sobre conectividade, ou mesmo à estrutura de websites, quando setorizam a participação do internauta em lócus de invisibilidade, e deixam de levar a participação cidadã para a arena principal, no combate à reprodução de guetos digitais.

Há a necessidade de abrir canais não apenas de participação, via e-mails ou comunidades virtuais segmentadas, por exemplo, mas de interconectividades capazes de redimensionar debates sobre $C \& \mathrm{~T}$, articulando a lógica da prática, saberes acadêmicos, representações sociais diversas. Problematizando questões de poder e permitindo que o público, em uma perspectiva mais horizontal de interatividade, faça parte do processo, exerça também sua dimensão autoral.

Como a ampliação de canais on-line de interatividade pode levar, de fato, à inclusão de indivíduos e grupos não só na esfera de debates e conhecimento, mas na esfera decisória, na formulação de políticas públicas, na definição de marcos regulatórios? As modalidades de interatividade digital na Comunicação Pública de C\&T demandam análises sobre processos de organização, visibilidade/ invisibilidade, efetividade/simulações, horizontalidade/ verticalidade, diversificação de contextos no traçado de objetivos. Neste estudo, discute-se o modus operandi da participação e da interatividade digital, em âmbito público, tendo em vista deslocamentos hierárquicos, somatória de competências, na lógica de produção, usos e mediações em C\&T. Dessa forma, foram também analisados sites e portais de C\&T no e-governe, a partir de reflexões sobre interatividade em produções jornalísticas. 


\section{Comunicação, Ciência e Política}

Para compreender a realidade dos estudos científicos, Bruno Latour, antropólogo e sociólogo francês, acompanhou e registrou, em textos e montagem fotofilosófica, detalhes da prática científica de pesquisadores que investigavam a floresta Amazônica, em 1991. As impressões de Latour, interligadas a questionamentos do campo científico, foram narradas no livro A Esperança de Pandora (2001). Tais percepções embora não dirigidas aos meios de comunicação e ao fazer jornalístico oferecem subsídios para pensar a Comunicação da Ciência e da Tecnologia no contexto virtual.

Ao discutir a construção de molduras antropológicas da ciência, Latour lança reflexões a temas caros ao jornalismo. Verdade, perspectivismo, realismo, construtivismo, transparências e ocultamentos são vigas do fuso argumentativo que Latour constrói brotadas do par filosófico por excelência aparêncialrealidade (PERELMAN; OLBRECHTSTYTECA, 2005, p.472). Discussões que se inserem no campo da política e no da Comunicação Pública, conceito multidisciplinar.

Tendo em vista políticas públicas de C\&T, a apropriação social nesse campo depende também da viabilidade e do fortalecimento da Comunicação Pública, que tem como parte importante de sua missão dar respostas a uma das indagações de Latour: "Como acondicionamos o mundo em palavras?" (LATOUR, 2001, p.39). O jornalismo da grande imprensa, dos sites, de estruturas comunicacionais do Estado, de pequenos veículos de comunicação tem como um dos objetivos-base reportar o acontecimento. Produção 
de textos "fiéis ao fato" (BRASIL, 2001, p.9), concretização da transparência (Id.), descrições de "facts, not rumours" (REUTERS, 2009) são pressupostos da atividade jornalística destacados em manuais de redação que, em geral, deixam de problematizar o perspectivismo na produção de notícias. As notícias sintetizam o real, e os manuais sintetizam a descrição da produção jornalística, ocultando complexidades, diversidade de interesses, intencionalidades.

Na experiência em meio à Floresta Amazônica, Latour observa cientistas intrigados com a transição savana-mata densa, cenários naturais lado a lado - pano de fundo de indagações prioritárias, extensivas ao fazer científico como um todo e, acredito, aplicáveis à Comunicação e ao jornalismo na Internet, em particular. Latour indaga: "As ciências falam do mundo? É o que se afirma [...]. As ciências não falam do mundo, mas constroem representações que ora parecem empurrá-lo para longe, ora trazê-lo para perto." Onde se lê ciências, lê-se também jornalismo. O jornalismo narra um mundo, em matérias de construções. Há confiabilidade, ao ser um porta-voz público, que historicamente está ligado ao surgimento da esfera pública (HABERMAS, 1984), tendendo a ocupar um Quarto Poder, posição questionada quanto mais em cenários de dependências mercadológicas ou alianças ideológicas.

Latour problematiza as visões de mundo oferecidas pela ciência - questionamentos extensíveis à Comunicação. Na análise de cenários de multiatores, Latour focaliza, entre circuitos possíveis, as relações entre política e ciência. Ao revelar diálogos empreendidos por Sócrates, reitera a importância da participação política, da retórica - vista como a 
aquisição dos meios argumentativos para participação nos debates públicos -, da própria política que lida "com uma multidão de não peritos" (LATOUR 2001, p.276). Denuncia um Sócrates que descarta a retórica, caracterizando-a como mera "simulação de política"; que reduz a nada estadistas gregos, elegendo-se como exemplo maior de autenticidade e verdade política. Comportamento a que hoje, ao criticar e rejeitar a política, muitos acabam incorrendo. Sócrates é, na fala de Latour, espelho de um discurso que predomina, inclusive entre a multidão de não peritos, que estrategicamente estão e são afastados do campo legítimo das discussões públicas. “Uma Atenas feita de Sócrates virtuosos não será melhor se o Estado for privado de sua forma específica de racionalidade [...]" (LATOUR, 2001, p.283).

A política vista por Sócrates se iguala à ciência fechada em si mesma, "sem discussão ou deformação", uma arma para abolir o diálogo, impor o silêncio, fazer calar, que não elimina irracionalidades nem torna seu próprio campo melhor (Ibid., p.296). E que, por fim, afasta-se da Comunicação, ao negar a importância da divulgação científica em geral - afastamento ainda mais radical e intransigente da Comunicação feita pelo Estado, por renunciar tanto a multidão dos leigos quanto a política, tachando-a de imoral. Sem meias-palavras, Latour ousa: "terei muito prazer em ser rotulado de 'anticientífico' se 'científico' tiver apenas esse primeiro sentido", o da "Ciência (№ 1)" da incomunicabilidade, entre outros adjetivos contraindicados.

Latour aponta outro sentido para "científico" (Ciência № 2) que não deseja abolir a política e, ao mesmo tempo, não é apolítico nem politizado, em um cenário onde a 
ciência está livre da política e a política está livre da ciência para poderem, finalmente, reunir-se, em movimentos de ordem e desordem. Porque "o que a Ciência № 2 precisa, contrariamente à Ciência № 1, é de muitas controvérsias, problemas, assunção de riscos e imaginação e de uma 'vascularização' com o resto do coletivo tão rico e tão complexo quanto possível" (LATOUR, 2001, p.297-298). "A informação necessária não é sobre o conteúdo da ciência, é sobre a relação entre os especialistas e os políticos, os meios de comunicação e o resto de nós", afirmam Collins; Pinch (2003, p.196), que defendem o esclarecimento público sobre a ciência e a demonstração de seus mecanismos internos de funcionamento, "pois questões científicas e tecnológicas figuram cada vez mais no processo político" (Ibid., p.195).

Os debates que surgem do encontro entre ciência e política se manifestam na junção Comunicação e Estado, da qual se depreende o conceito de Comunicação Pública. As controvérsias dizem respeito à esfera política que, historicamente, desperta infindáveis suspeitas, como destacado por Latour. "Jamais alguém pôs em dúvida que verdade e política não se dão muito bem uma com a outra, e até hoje ninguém, que eu saiba, incluiu entre as virtudes políticas a sinceridade" (ARENDT, 1997, p.283). Trata-se de uma visão maquiavélica de política como sendo alheia à moral (LATOUR, 2001, p.290).

Diante de tal sentença, comoé possível a prática da transparência pela Comunicação Estatal, objeto ao qual se volta este estudo? Norberto Bobbio, unindo as reflexões sobre verdade e política à análise da Comunicação Estatal, usada em seu texto como sinônimo de Comunicação Pública, não 
chega a conclusões diferentes de Arendt. Bobbio afirma (1986, p.102): “[...] o ocultamento é fenômeno comum a todas as formas de comunicação pública".

O ocultamento é comum ao poder. Nada surpreendente é que a Comunicação Estatal silencie e esconda o que o próprio poder deseja ocultar. Como, então, prosseguir por esse caminho, sem a fabricação de ilusões de Comunicação Pública? Seria enganosa a escolha por exaltar o uso da tecnologia na comunicação dos atos públicos, como se a propagação de textos e de imagens, quebrando a limitação tempo-espacial, por si só, garantisse o "desocultamento" do poder. Por outro lado, não é correto lançar conclusões precipitadas sobre o objeto de pesquisa, negando toda e qualquer possibilidade de transparência pública, promovida pela Comunicação Estatal. As polaridades são, nesse caso, desaconselháveis, simplistas. Por isso, a investigação exige o encontro com ideias contrastantes, a identificação de paradoxos, um caminhar cuidadoso e multidisciplinar, para que, enfim, novo caminho surja, de preferência conciliando sua utilidade descritiva e normativa.

A evocação de Hannah Arendt, ao tratar do desencontro entre verdade e poder, dirige o olhar para a problemática do objeto, sem, porém, circunscrever-se a ela. Após discorrer sobre todos os problemas da política, em seu elucidativo livro Entre o passado e o futuro, Arendt (1997, p.325) conclui vislumbrando possibilidades para o que também representa a política - um estado de "recompensadora alegria que surge de estar na companhia de nossos semelhantes, de agir conjuntamente e aparecer em público, de nos inserirmos no mundo pela palavra e pelas ações, adquirindo 
e sustentando assim nossa identidade pessoal e iniciando algo inteiramente novo".

Embora o pensamento de Arendt seja, por vezes, considerado radicalmente pessimista diante da política (LAVALLE, 2001, p.53), a filósofa parece propor, através da crítica incisiva, uma espécie de questionamento permanente da política, um passo além do desencanto, evitando idealizações. A conclusão baseia-se nas seguintes palavras de Arendt (1997, p.324-325):

[...] Falei como se o âmbito político não fosse mais do que um campo de batalha de interesses parciais e antagônicos, onde nada contasse senão prazer e lucro, partidarismo e ânsia de domínio [...]. Todavia, o que eu queria mostrar aqui é que toda essa esfera, não obstante sua grandeza, é limitada - ela não abarca a totalidade da existência do homem e do mundo [...]. É somente respeitando os seus próprios limites que esse âmbito, onde temos a liberdade de agir e de modificar, pode permanecer intacto, preservando sua integridade e mantendo suas promessas. Conceitualmente, podemos chamar de verdade aquilo que não podemos modificar; metaforicamente, ela é o solo sobre o qual nos colocamos de pé e o céu que se estende acima de nós.

Sendo um empreendimento humano dotado de suas limitações e fragilidades intrínsecas, a política pode e deve ser discutida e modificada. Mas jamais sairá imune diante da verdade filosófica, como nós mesmos não sairíamos. Os ideais normativos, em vez de cegar, podem limpar os olhos para o diagnóstico da realidade, sem levar à inação, 
na constatação do que não pode ser alcançado: "pertence à essência mesmo do poder ocultar-se" (BOBBIO, 2000, p.389). A admissão dos limites e das incoerências é o único modo seguro de não se sobrepujar à realidade, mas modificá-la, com afinco. A política fundada na justiça só se concretiza em um espaço público de questionamento. Política não é assunto para alguns. A Comunicação ocupa importância central nesse processo, podendo tanto viabilizar o debate democrático, quanto arrefecê-lo.

\section{Comunicação Pública}

Não se pode falar em Comunicação Pública para a Ciência e Tecnologia, seja do domínio estatal ou privado, sem que estejam presentes três requisitos base: prestação de informações (subprincípio da informação), informação significativa (subprincípio da motivação) e participação (subprincípio da participação). A tríade apontada integra a lei de Transparência Administrativa presente na Constituição de 1988 e desenvolvida em leis subsequentes ${ }^{1}$, que deveria fundamentar, sobretudo, modelos de comunicação do Estado, sejam dos poderes Legislativo, Executivo ou Judiciário (BARBOSA, 2009). Para que a comunicação organizacional do Estado se configure como Comunicação

1 Os subprincípios foram garantidos pela Constituição de 1988, no art. 37. $\S 3^{\circ}$. I a III, e aperfeiçoados com leis subsequentes, tais como a Lei do Processo Administrativo (Lei n. 9.784, de 29/01/99), Lei da Responsabilidade Fiscal (Lei Complementar n.101, de 04/05/2000), que inclui a divulgação por meios eletrônicos e cibernéticos (art. 48), Lei n.10.257/2001 (arts. $2^{\mathrm{o}}$, II e XII, 4 으, III, f e s, $40, \S 4$, 43 e 44) e o Estatuto da Cidade (Lei n. 10.257, de 10/07/2001) (MARTINS, 2004). 
Pública, é imprescindível a intersecção entre transparência legal e direitos à informação e à comunicação.

Contudo, a ideia de transparência, em uma perspectiva filosófica, é alvo de críticas de estudiosos como Jacques Rancière e Dominique Wolton (BARBOSA, 2009). Entre os críticos da transparência, encontra-se também Latour, que identifica em Rousseau a gênese do conceito de transparência aplicado à política, para o qual o "Estado é transparente para si mesmo, livre das manipulações, dos obscuros segredos" (LATOUR, 2001, p.302) - Estado idealmente asséptico.

Contudo, a obsessão de Rousseau por transparência leva-o à ruína (STAROBINSKI, 1991, p.24). Qual Ícaro em direção ao Sol, Rousseau entrega-se inteiramente ao ativismo político por um mundo restaurado e firmado em contratos sociais transparentes. Mas não se alcança a transparência por meio de invenções e soluções técnicas ou filosóficas, sem antes ter a própria estrutura perdida em sua imensidão de desejos, imersa.

Para Latour, ao pretender livrar o Estado de todas as suas deformações, Rousseau o torna "ainda mais monstruoso" (2001, p.302). Bobbio, já convencido por exemplos históricos, rememora em caráter de urgência: é próprio do poder o ocultamento. É próprio da humanidade. Por isso, deixaríamos de querer "ver", sem disfarces e obstruções?

As definições e aplicações do conceito de transparência, que Wolton (1997), Rancière (2007) e Latour (2001) denunciam, configuram-se, de fato, uma ameaça à vida pública. Tais definições colocam de lado questões basilares - $\mathrm{a}$ inclusão do outro e a interatividade -, como bem sinaliza Wolton; concentram-se na decadência moral dos políticos, corrupções 
que misturam cenas passionais e obsessão por dinheiro, como destaca Rancière; ou são usadas para defender um cenário utópico, que obstaculiza a participação pública consciente e inviabiliza a política, como assinala Latour.

Se entendido apenas como visibilidade de atos políticos, mera prestação de informações, denuncismo de corrupções políticas, máquina de revelação de escândalos ou ideia artificial que serve para deturpar a identidade da esfera política, o conceito de transparência configura-se como alvo de críticas, ainda que não se possa rejeitar o valor das denúncias públicas enquanto conquistas democráticas. Basta considerar as ações necessárias da Transparência Brasil, por exemplo, ou de práticas consistentes de investigação jornalística.

Contudo, transparência é mais do que ser visto ou fabricar imagens de democracia que, quando muito, mantêm elos fracos de correspondência com o real. No campo das leis brasileiras, o conceito ganhou status constitucional em 1988 - conquista democrática que fundamenta a análise central da aplicação da transparência à Comunicação (BARBOSA, 2009). Wallace Martins (2004) afirma que o poder transparente não apenas deve prestar informações sem manipulação, mas contemplar três aspectos vigentes no ordenamento jurídico, destacados na seguinte tríade legal:

1. Subprincípio da informação;

2. Subprincípio da motivação;

3. Subprincípio da participação.

Esse tripé democrático, se aplicado à Comunicação, oferece sustentação necessária à Comunicação Estatal. Tais 
conceitos quando discutidos à luz da Teoria da Comunicação ganham subsídios para a construção de uma Comunicação Pública atenta aos direitos à informação e à comunicação no Estado Democrático de Direito.

O subprincípio da publicidade ou publicidade legal consiste na prestação de informações factuais nos formatos propagandístico, oficial ou jornalístico. Na perspectiva jurídica, consiste na prestação de informações com veracidade, moralidade, imparcialidade e impessoalidade. Conforme apontado por Latour, a ciência constrói visões de mundo. No campo do jornalismo, reconhece-se o relato subjetivo, perpassado por diferentes interesses. A admissão da parcialidade faz parte da transparência como meio de proteção à verdade factual. Já a exigência de veracidade no campo do jornalismo deve ser discutida a partir de perspectiva filosófica, na teoria do conhecimento e na experiência cotidiana. Gomes (2005) destaca a importância do acordo universal, do agir plural, definido por uma comunidade de comunicação, para estabelecer a veracidade de um relato. A crítica da verdade é central ao relato jornalístico.

No entanto, a transmissão de informação isoladamente pode levar à visibilidade, mas não à transparência. Além de informar, é imprescindível conferir significação. Em sites públicos, não basta disponibilizar documentos, digitalizar relatórios ou relatos taquigráficos de reuniões de decisões - ações que deveriam ser garantidas legalmente -, é necessário dar sentido às informações, conectá-las, ordená-las. O jornalismo, ao oferecer textos explicativos, que visem à contextualização, à demonstração de causas e consequên- 
cias, em uma linguagem convidativa, confere significação, acessibilidade a saberes-chave, promove o conhecimento.

Em sites, a produção jornalística aumenta a possibilidade de significação, com dispositivos multimídia, em que som, texto, imagens, vídeos podem ser reunidos para contar a notícia. Os links oferecem a possibilidade de remeter a documentos oficiais, e-mails de autoridade, outras produções noticiosas, representações da sociedade civil, além de elementos de design. O conceito de rede se fortalece com a disponibilidade de notícias multimídia, e de atratividade visual, bem como de dispositivos explicativos de caráter mais técnico sobre navegabilidade, por exemplo, para ajudar na inclusão à cultura digital.

Oferecer informações incorporadas de significações por si só atende, em parte, à exigência da interatividade, considerando as diversas concepções do conceito. Os links em textos noticiosos promovem interações diversas. Servem para promover a interconectividade entre as milhares de unidades informativas de um site estatal, que facilmente levam ao caos informativo; remeter a matérias de opinião que poderiam ser tanto de jornalistas quanto de cientistas, políticos e cidadãos ligados ao assunto; conectar o internauta aos atores citados na notícia, disponibilizando fotos, e-mails, canais de participação; recontar com mais detalhes e precisão o acontecimento.

Contudo, o subprincípio da participação exige mais. $\mathrm{Na}$ lei, o dever da participação envolve pesquisa de opinião, enquete, participação indireta via ombudsman, mecanismos de audiência e consulta públicas, direito de petição (quando o cidadão faz requisição de participação e emite sugestões 
ou cobra punição de atos públicos ilícitos), entre outros mecanismos (MARTINS, 2004). Aplicado à Comunicação digital, o subprincípio da participação pressupõe disponibilização do e-mail do webmaster, editores, jornalistas; matérias jornalísticas assinadas; contato dos políticos (endereço, fax, telefone, e-mail); destaque para legislação participativa; espaço para manifestação de diferentes grupos; possibilidade de recebimento de boletim eletrônico ou de acompanhamento de decisões e debates; abertura para comentários e críticas do leitor; abertura para discussão, por intermédio de fóruns, blogs, chats e outras formas de interação; sites ou blogs de cientistas e políticos; orientação sobre participação e interação no portal; resultados das participações e de seu impacto na decisão de autoridades políticas; planejamento, execução e divulgação de projetos para garantir a interatividade no portal; seção para grupos específicos (mulheres, jovens, crianças); sala de imprensa, ombusdman; enquetes, acessibilidade, resposta a e-mails.

Todo o princípio da Transparência Administrativa lei destinada a reger a Administração Pública - deve ser estendido à Comunicação. "A Comunicação não é uma ferramenta da publicização legal, restrita a diretriz instrumental, mas deve ser vista pelo próprio Estado como uma esfera pública comunicacional, obedecendo às regras legais que propõe" (BARBOSA, 2009). Para chegar a essa compreensão, torna-se imprescindível também o envolvimento de comunicadores com o mundo das leis, contribuindo com o avanço da legislação dos direitos à informação e à comunicação, que ainda carece de decisões legais e regulamentações. 
Com o avanço da Comunicação Estatal, e sua incursão no fazer jornalístico, o termo Comunicação Pública vem sendo apropriado pelo Estado para definir a sua prática jornalística. No entanto, a Comunicação Estatal só se torna pública quando está comprometida com o "bem comum" e atende aos requisitos de transparência pública.

A supremacia do interesse público (JUSTEN FILHO, 2006), definida na Constituição, deve caracterizar a Comunicação do Estado. "Juridicamente, efetivo titular do interesse público é a comunidade, o povo" (Ibid., p.36). Segundo Justen Filho, o interesse público não se confunde com o interesse do Estado, do aparato administrativo ou do agente público. "O conceito de interesse público é muito complexo, pois as interpretações são conflituosas", afirma Edgar Rebouças (2008). Diante da complexidade do termo, é necessário que haja canais de comunicação para que os diversos segmentos da sociedade, em conjunto com o Estado, se manifestem, interajam, estabeleçam intercâmbio e visem a resoluções estabelecidas democraticamente.

Ao manter um portal, o Ministério da Ciência e Tecnologia ${ }^{2}$, por exemplo, deve atender à transparência legal não apenas no que diz respeito à publicização de contas públicas ou à disponibilização de informações. A Comunicação não deve ser vista como um instrumento em correspondência a um subprincípio da transparência, mas precisa incorporar o dever de informar e, principalmente, de agregar significação e promover a participação e a interatividade - conceito que significa, sobretudo, troca, feedback.

2 Disponível em: $<$ http://www.mct.gov.br $>$. 
“O papel do conhecimento científico como prática de libertação social, porém, é ainda pouco discutido, assim como as discussões que envolvem política científica", afirma Graça Caldas (2004, p.29) ao defender a importância da Comunicação Pública para a ciência cidadã. Comunicação que precisa estar atenta à fala de Latour: "uma ciência sempre oculta outra" (LATOUR, 2001, p.47). Latour revela processos implícitos no fazer científico. Cabe ao jornalista também a desocultação. Quais os atores envolvidos, seus interesses, a relação entre temas, ramificações históricas, sociais, econômicas, políticas do acontecimento. Conexões e circuitos que se desdobram, e precisam ser conhecidos e debatidos por um público mais amplo.

\section{Interatividade digital e produção jornalística}

Da tríade da transparência, embora com subprincípios estreitamente inter-relacionados, o desafio maior recai na "inclusão do outro" - na interatividade. Em revelar interatividades ocultas - cenas de poder e interesses -, em desocultar cidadanias submersas, impedidas da participação. Há também, como mencionada na seção anterior, a interatividade dos links de textos noticiosos. O jornalismo digital funciona como olhar unificador em páginas eletrônicas e, ao mesmo tempo, pode desdobrar o acontecimento em multiconexões digitais, ampliando a visão sobre o mundo, ao permitir o perspectivismo via palavras e imagens, com seus entrevistados e fontes; via técnica, com dispositivos web.

Latour fala do olhar unificador. Conta da bióloga Edileuza Sette Silva, que na expedição na floresta, coleta 
ampla variedade de plantas, recolhe as "provas", depois classifica, etiqueta, emite relatórios. O todo imenso é apreendido em partículas, desafios de tempo e espaço são vencidos, e a floresta que se distancia no laboratório, também se torna mais presente. Como uma jornalista, Sette Silva é a mediadora. Oferece a floresta, sob olhar que organiza e unifica e, igualmente, amplia. Latour conclui: ir à floresta não é para todos, e há inconvenientes, obstáculos "as pessoas se perderiam nela", "o calor seria tremendo".

Além disso, a pesquisadora, ao colar as folhas e caules de plantas em papéis, e reunir suas imagens com legendas, pode fazer reanálises, escrever ao lado da pesquisa. "A distância supostamente vasta entre palavras e coisas restringe-se agora a alguns centímetros" (LATOUR, 2001, p.52). Há mais vantagens nesse processo de recortes e transporte daquilo que será objeto de estudos. Espécimes de mil quilômetros de distância e outras colhidas, há três anos, tornam-se contemporâneas, avizinhadas, compondo "quadro sinótico". A mobilidade é considerada decisiva: a posição dos espécimes pode ser mudada. Plantas tornam-se móveis, recombináveis "como os caracteres de chumbo de um monotipo" (Ibid., p.54).

Os relatos de Latour podem ser estendidos à construção da notícia e sua presença na web, na superação tempo-espaço. No jornalismo hipermídia não há, ou deveria haver, apenas um ator-emissor, isolado, digitando caracteres pouco móveis. Na construção de seu relato, espera-se por palavras em conectividades. O jornalista é apenas o primeiro ator-emissor. Os links devem remeter a outras autorias de significação sobre o reportado. Como Sette Silva, os atores- 
emissores que se sucedem, vindos à existência por meio de compromisso jornalístico pela apropriação do conhecimento, devem ter o direito de escrever ao lado das "provas", reexaminá-las, recombinar informações em monotipos digitais, e seus bytes. Com vantagens no mundo tecnológico: o acontecimento, em comparação ao estudo específico da floresta a que Latour faz referência, pode estar mais próximo. Não apenas pela foto, que ilustra o texto. Não apenas pelo texto e infográficos, que reescrevem o fato. Não apenas por documentos oficiais e notas taquigráficas de encontros públicos possíveis de serem alcançados por uma reunião de links. Ou por vídeos que oferecem os eventos. E narrações radiofônicas, de outros jornalistas, que lançam olhar diverso sobre o acontecimento. Não só por links que remetem ao texto do cientista e do político - opiniões não editadas. Links que deveriam remeter ao olhar cidadão, do indivíduo que desejou escrever mais linhas sobre determinado assunto. Não apenas por essa extensiva possibilidade de rememorar o acontecimento através de tecnologias e design, mas a proximidade e a apropriação dizem respeito, principalmente, àquilo que é mais caro à Comunicação - o religare.

A interatividade está ligada à relação entre diferentes indivíduos e grupos e à conversação democrática. Schudson (2004) defende enfoque realista e coerente sobre a conversação que gera democracia. Para ele, ao se referir à comunicação face a face, essa troca pública de pontos de vista nada tem de livre, espontânea e igualitária. É, sim, regida por regras, segundo interesses pré-determinados, perpassada por vieses de múltiplas intenções. Primeiro, que nem todos estão habilitados automaticamente à discussão pública. Segundo, que a conversação implica controvérsia 
não consensos, que por vezes se mostram predominantes mesmo durante o processo.

Aplicada à conversação na Internet, as considerações de Schudson (2004) permitem reflexões sobre estruturas de poder e interação digital, embora no artigo considerado, as notícias e registros escritos são vistos como resultado final da conversação, ou a mola propulsora inicial da agenda pública, ou ainda memorial público. Ainda assim, há subsídios importantes para pensar o entrelaçamento, em âmbito virtual, da notícia e da conversação. Espaços de participação, publicação de comentários sobre notícias e artigos virtuais, inserção de textos de autorias extrassite ou extraesfera de poder, a identificação do jornalista que escreve a notícia e seu respectivo e-mail levam à participação. $\mathrm{O}$ "fazer parte de", em uma página on-line estatal, estimula a interação e as conversações entre jornalista-internauta, entre internautas, com atores diversos, políticos e cientistas, que compõem a notícia, desde que, do ponto de vista técnico, recursos web estejam disponíveis.

Ao tratar da conversação face a face, Schudson reconhece que o medo do outro, o constrangimento, as coerções sociais induzem ao silêncio. O ponto forte da conversação presencial, que seria a espontaneidade, não passa de promessa democrática não cumprida. Nesse sentido, a Internet, por favorecer o anonimato, torna-se um meio aparentemente propício para prover diálogos, ainda que a participação em sites estatais, quando ocorre, tem se restringido ao textual, sem a participação multimídia, por exemplo, que poderia incluir gravações sonoras e de vídeos, não restrita apenas a razões públicas argumentativamente textuais. É preciso 
haver diferentes modalidades de participações ainda que não atendam, em um primeiro momento, às manifestações argumentativas necessárias ao debate público, ou se percam momentaneamente em discussões insolúveis. Um conceito de democracia "ou de local de conversação deverá ter que considerar os instantes onde o diálogo é por ele mesmo um impedimento para o cumprimento da democracia" (SCHUDSON, 2004, p.78).

A existência do mediador que centraliza na produção jornalística a movimentação democrática de um site estatal tem de coexistir com o lugar fixo e, concomitantemente, com a ultrapassagem da setorização de quem participa. Desse modo, pode haver grupos de discussão temáticos e espaços reservados à expressão da diversidade, mas o localismo participativo precisa ser superado, assim como o dualismo entre opinar e decidir. Espera-se por deslocamentos de centros de poder, recolocação de centros fixos de cidadania, movimento da participação a subverter estratégias restritivas do processo comunicativo em um site.

Nesse percurso, o jornalista ocupa posição central - reúne textos, imagens, sons, atratividade, links que estabeleçam associações diversas, ordem na escalada informativa - e o internauta conquista espaços fixos, mas não rígidos. Suas conversações, em lócus digitais oferecidos pelos sites, podem ficar restritas aos pares, podem também ser reunidas a outras conversações em textos que unifiquem a diversidade, lançando-a à arena da visibilidade pública. Para tanto, mais uma vez o jornalista mediador, consciente de seu papel unificador e contrário à individualização excessiva, agita o cenário, informa reunindo, dialoga 
permitindo a conversação, contribui ativamente para que o que está de fora não apenas seja um visitante relutante, em quase segredo, em comentários de rodapé, pouco interrelacionado, mas adentre conjuntamente em esferas cada vez mais sobressalentes, até atuar e ajudar a decidir.

O jornalismo estatal, portanto, é fator estratégico para estimular a interatividade, ao prover interação entre diferentes conteúdos de um site, mas, sobretudo, ao conferir à página bidirecionalidade, resposta aos cidadãos-internautas, descentralizações de poder, localização da participação, superação da segmentação, envolvimento do internauta no processo político. Tendo em vista a posição estratégica do jornalista no serviço público, é necessário também que se discuta mais amplamente a realidade dos concursos públicos, uma vez que não há regulamentação específica para a legislação que rege os concursos no País (BARBOSA, 2010).

\section{Interatividade em sites de C\&T}

A interatividade em sites públicos de C\&T ainda é um recurso subexplorado, apesar de central para a inclusão da cidadania. As conclusões se baseiam em pesquisa sobre interatividade em notícias on-line de 20 instituições de C\&T do e-governe (Tabela 1), sendo que quatro das instituições não oferecem serviço de notícias e a página de um site não estava disponível (INT). 
Tabela 1. Instituições de C\&T.

\begin{tabular}{|c|c|c|}
\hline Instituições em C\&T - E-governe & $\mathrm{UN}^{*}$ & $\begin{array}{l}\text { Indicação de } \\
\text { referências das UN }\end{array}$ \\
\hline Ministério da Ciência e Tecnologia (MCT) ${ }^{2}$ & 2 & $\begin{array}{l}\text { OVÁRIO, } 2010 . \\
\text { PESQUISADOR, } 2010 .\end{array}$ \\
\hline Centro Brasileiro de Pesquisas Físicas $(\mathrm{CBPF})^{3}$ & 2 & $\begin{array}{l}\text { LIMA, } 2010 . \\
\text { PASCUETO, } 2010 .\end{array}$ \\
\hline $\begin{array}{l}\text { Centro de Excelência em Tecnologia Eletrônica } \\
\text { Avançada (Ceitec S.A.) })^{4}\end{array}$ & --- & ------ \\
\hline Centro de Tecnologia Mineral (Cetem) ${ }^{5}$ & 2 & $\begin{array}{l}\text { FREITAS, 2010a. } \\
\text { FREITAS, 2010b. }\end{array}$ \\
\hline $\begin{array}{l}\text { Centro de Tecnologias Estratégicas do Nordeste } \\
\text { (Cetene })^{6}\end{array}$ & 2 & $\begin{array}{l}\text { DIRETOR, } 2010 . \\
\text { PRESIDENTE, } 2010 .\end{array}$ \\
\hline $\begin{array}{l}\text { Centro de Tecnologia da Informação Renato Ar- } \\
\text { cher }(\mathrm{CTI})^{7}\end{array}$ & 2 & $\begin{array}{l}\text { CTI, } 2010 . \\
\text { LATIN, } 2010 .\end{array}$ \\
\hline $\begin{array}{l}\text { Instituto Brasileiro de Informação em Ciência e } \\
\text { Tecnologia (IBICT) })^{8}\end{array}$ & 2 & $\begin{array}{l}\text { ESPECIALISTAS, } 2010 . \\
\text { LANÇADA, } 2010 .\end{array}$ \\
\hline $\begin{array}{l}\text { Instituto de Desenvolvimento Sustentável Ma- } \\
\text { mirauá (IDSM) }\end{array}$ & 2 & $\begin{array}{l}\text { REIS, } 2010 . \\
\text { RAMOS, } 2010 .\end{array}$ \\
\hline $\begin{array}{l}\text { Instituto Nacional de Matemática Pura e Aplica- } \\
\text { da }(\operatorname{Impa})^{10}\end{array}$ & --- & ------ \\
\hline $\begin{array}{l}\text { Instituto Nacional de Pesquisas da Amazônia } \\
(\text { Inpa })^{11}\end{array}$ & 2 & $\begin{array}{l}\text { MORENO, } 2010 . \\
\text { JORDANO, } 2010 .\end{array}$ \\
\hline $\begin{array}{l}\text { Instituto Nacional de Pesquisas Espaciais } \\
\text { (Inpe })^{12}\end{array}$ & 2 & $\begin{array}{l}\text { GILBERTO, } 2010 . \\
\text { CST/INPE, } 2010 .\end{array}$ \\
\hline Instituto Nacional do Semiárido (Insa) ${ }^{13}$ & 2 & $\begin{array}{l}\text { SBPC, } 2010 . \\
\text { APROVADA, } 2010 .\end{array}$ \\
\hline Instituto Nacional de Tecnologia (INT) ${ }^{14}$ & --- & ----- \\
\hline Laboratório Nacional de Astrofísica (LNA) & -- & ----- \\
\hline $\begin{array}{l}\text { Laboratório Nacional de Computação Científica } \\
(\text { LNCC })^{15}\end{array}$ & 2 & $\begin{array}{l}\text { JORNADA, } 2010 . \\
\text { LNCC, } 2010 .\end{array}$ \\
\hline Laboratório Nacional de Luz Síncrotron (LNLS) ${ }^{16}$ & 2 & $\begin{array}{l}3^{\circ} \text { CONGRESSO, } 2010 . \\
\text { LNLS, } 2010 .\end{array}$ \\
\hline Museu de Astronomia e Ciências Afins (MAST) ${ }^{17}$ & --- & ------ \\
\hline Museu Paraense Emílio Goeldi (MPEG) ${ }^{18}$ & 2 & $\begin{array}{l}\text { BOAS, } 2010 . \\
\text { PROGRAMAÇÃO, } 2010 .\end{array}$ \\
\hline Observatório Nacional $(\mathrm{ON})^{19}$ & 1 & DIA, 2010. \\
\hline Rede Nacional de Ensino e Pesquisa $(\mathrm{RNP})^{20}$ & 2 & $\begin{array}{l}\text { I ENCONTRO, } 2010 . \\
\text { MINISTRO, } 2010 .\end{array}$ \\
\hline
\end{tabular}

*UN (Unidades noticiosas). 
Na análise de 29 notícias jornalísticas dos sites e portais em C\&T mantidos pelo governo federal ${ }^{3}$, em $93,1 \%$ não há o e-mail do jornalista ou editor responsável na mesma página da notícia, sendo que em $72,4 \%$ não há sequer o nome do autor da notícia. A despersonalização da produção jornalística agiganta a instituição face ao internauta, atua como fator de desestímulo à participação.

Em nenhuma das unidades noticiosas consideradas, há recursos multimídia (som, rádio, vídeo) ou qualquer espaço de participação, não sendo possíveis ao internauta, portanto, ações simples como ter seu comentário publicado no site ou ler comentários de outros participantes.

Há algumas iniciativas isoladas que apontam para um caminho de maior interatividade digital. Nas notícias analisadas do site da CBPF, há o nome das jornalistas, além de e-mails e contato telefônico ${ }^{4}$. Uma delas informa o MSN e Skype ${ }^{5}$. Nas notícias do Inpa, há link para o Twitter ${ }^{6}$. Quanto

3 As referências das notícias estão disponíveis no final do deste estudo. Uma tabela com a descrição da pesquisa e links para as unidades noticiosas está disponível no seguinte endereço eletrônico: $<$ http://sites.google. $\mathrm{com} /$ site/comcienciatecnologia/>. Como critério de análise, foram consideradas as duas últimas notícias publicadas no mês de novembro de 2009. Nos casos em que não há matérias na data definida, foram selecionadas as duas últimas notícias, independentemente do mês de publicação.

4 LIMA, Dayse. Morre, aos 95 anos, Marcello Damy, precursor da física nuclear no Brasil. Disponívelem:<http://portal.cbpf.br/index.php?page=Noticias. VerNoticia\&id=311> Acesso em: 2 jan. 2010.

PASCUETO, Cínthia. Ciência às 6 e meia discute os rumos da astronomia frente aos avanços tecnológicos. Disponível em: <http://portal.cbpf.br/ index.php?page=Noticias. VerNoticia\&id=310> Acesso em: 2 jan. 2010.

5 LIMA, Dayse. Morre, aos 95 anos, Marcello Damy, precursor da física nuclear no Brasil. Disponívelem:<http://portal.cbpf.br/index.php?page=Noticias. VerNoticia\&id=311> Acesso em: 2 jan. 2010.

6 Disponível em: $<$ http://twitter.com/ascom_inpa> 
à utilização de links para documentos e informações adicionais, além de links para sites e e-mails, em $68,9 \%$ o recurso está ausente. Exemplos positivos podem ser encontrados em notícia do IBICT que disponibiliza link do edital sobre projetos de implantação de repositórios institucionais para instituições públicas federais, estaduais e municipais de ensino e pesquisa ${ }^{7}$ e do RNP em notícia que trata do Fórum da Cultura Digital Brasileira ${ }^{8}$, com links para o site e a carta do Fórum?

A Internet possibilita a interação, como nenhum outro meio de comunicação, o que não significa que a interatividade seja automaticamente parte da essência dos sites. A tecnologia é o objeto-instituição, a somatória de grupos de mediadores e interesses reunidos com sentidos definidos. O artefato eletrônico e digital é composto de elementos visuais e arquitetura de poder manifestada na presença ou ausência de softwares interativos, constituição de bancos de dados, usos de linguagens de programação web, interfaces interativas, graus de usabilidade. Por estar na rede, não significa que uma instituição estatal tenha incorporado a descentralização do poder e a existência de receptoresemissores no funcionamento de seu site. Páginas on-line não implicam necessariamente transparência embora a uti-

7 LANÇADA nova chamada do edital para estimular implantação de repositórios institucionais. Disponível em: <http://www.ibict.br/noticia. php?page $=0 \&$ id $=675>$ Acesso em: 7 jan. 2010.

8 Disponível em: $<w w w . c u l t u r a d i g i t a l . b r>$.

9 Disponível em: <http://culturadigital.br/seminariointernacional/2009/11 /22/carta-da-cultura-digital-brasileira/>. 
lização do termo seja recorrente ${ }^{10}$, demandando reflexões sobre atribuições e usos de significados.

\section{Conclusão}

\section{Da Comunicação Digital à apropriação social}

Para contribuir com a apropriação social do conhecimento, as divulgações científicas em sites públicos de C\&T devem incluir necessariamente participação, heterogeneidades, conversas, dissenso, a partir de diferentes estratégias e adequações em função da diversidade do público-alvo. A Comunicação Digital deve atuar com olhar unificador capaz de, ao mesmo tempo, amplificar a interação por meio de dispositivos de tecnologias web e intencionalidades democráticas, em um processo de constante autocrítica e abertura à crítica cidadã.

Cabe ao Estado fomentar o debate público e, de fato, incluí-lo na esfera decisória, de modo a haver mais do que visibilidades, para que nos aproximemos da transparência que gera democracia. Cabe também às instituições, à sociedade civil organizada, a cada indivíduo assumir seu espaço, adentrar na esfera da política, exigir seu lugar na

10 A palavra é encontrada sob domínio do Estado (Portal da Transparência, Transparência - Portal da Câmara dos Deputados, Ministério da Justiça - Programa de Transparência, Transparência Pública), circula entre acadêmicos e a sociedade civil organizada (ONG Transparência Brasil, Transparência, Consciência \& Cidadania, Caminhos da Transparência), é discutida e teorizada internacionalmente (ONG Transparency International). Está também em páginas de jornais e revistas. Permeia um desejo social de reconstrução do mundo. Perpassa diferentes campos de estudos, tais como a Filosofia, Arquitetura, Ciências da Religião, Ciência Política, Direito, Comunicação, Administração, Economia, Medicina. 
esfera digital pública, para debater e ter o direito de influir em decisões sobre assuntos públicos.

Para os que dominam as regras do discurso e fazem parte de uma minoria pronta para participação, o Estado deve criar canais que levem à conversação, incentivando a heterogeneidade. Estratégias de publicidade pública deveriam incentivar a participação em sites estatais pelos quais passa - ou deveria passar - o fuso argumentativo das decisões políticas. Schudson (2004, p.75) faz alerta importante: “[...] a conversação democrática é uma conversação que não ocorre entre íntimos, nem mesmo entre estranhos, mas entre cidadãos que são informados de sua cidadania". Se não se pode inserir parcela significativa do público no debate on-line em um primeiro momento, que se atraia um público capaz de exercer seus direitos de modo que acabe por estender gradativamente as conquistas democráticas, inclusive o acesso à informação e à comunicação públicas.

A tecnologia, ainda que alegadamente a serviço da transparência, está sob controle e, também, subverte o controle. Faces que precisam ser realisticamente criticadas - o portal é público, mas deixa de cumprir importantes exigências públicas se não insere a participação e interatividade -, e elogiosamente reconhecidas - reconhecimento, por exemplo, de trabalhos jornalísticos que oferecem alternativa ao denuncismo, e levam ao conhecimento do cidadão fusos argumentativos e decisórios de temas que regem o funcionamento da Nação, entre outros aspectos. "As técnicas, porém, não são fetiches. São imprevisíveis, mediadores e não meios, meios e fins ao mesmo tempo: eis porque se esteiam no tecido social" (LATOUR, 2001, p.226). 
A arquitetura de poder de uma instituição, suas marcas históricas e sociológicas definem, mas não completamente, sua estrutura comunicacional, e mesmo seus artefatos eletrônicos. A tecnologia foge ao controle, é também somatória diversa, pode ultrapassar imposições, e surpreender em sua capacidade de transformação. As limitações na transparência comunicacional, com ênfase à prestação de informações, podem ser contrabalançadas com a disponibilização de relatos taquigráficos e cópias digitais de documentos originais de reuniões públicas, por exemplo. $\mathrm{O}$ que antes, a muito custo, só era adquirido presencialmente, pode estar em lócus digital público. Nesse sentido, são imprescindíveis dispositivos legais para garantir o acesso público on-line a documentos e informações públicas, o que requer o envolvimento ativo de jornalistas, cientistas, acadêmicos, cidadãos no campo das leis em favor dos direitos à informação e à comunicação no ambiente digital.

Há também formas híbridas de interação em formatos que não contemplam a conversação ou participação do internauta de maneira minimamente satisfatória, contudo, oferecem uma estrutura jornalística cada vez mais hipermídia, com links que promovem a interação entre diferentes conteúdos do portal sobre o assunto abordado, ampliando as possibilidades de transparência. No entanto, o relato jornalístico precisa estar em correspondência ao fato que o gerou, e atender a outros requisitos que promovem sua significação como exposição de causas, consequências, linguagem acessível, glossário virtual etc.

Prover educação política coletiva, cumprir direitos de acesso à tecnologia e às condições de conectividade são algumas das ações imprescindíveis para o debate público 
digital em C\&T. Ao considerar a Comunicação Pública Digital, tendo em vista a transparência aplicada a websites, participação e interatividade são requisitos essenciais nesse processo. Requisitos que precisam ser priorizados no cenário web da Comunicação Estatal, para expandir sua função pública ao diminuir a distância entre o público, em sua diversidade, e o universo de C\&T; ao incorporar conflitos, debates, dissensos e consensos, reinterpretações, construções e decisões conjuntas. A fidedignidade do mundo acondicionado em palavras - mundo cada vez mais digitalizado - está interligada estreitamente ao agir plural.

\section{Referências}

ARENDT, H. Entre o passado e o futuro. 4.ed. São Paulo: Perspectiva, 1997.

BARBOSA, H. Transparência pública e parlamento eletrônico: A reforma do poder Judiciário no portal do Senado Federal/2000-2004. São Bernardo do Campo. Programa de Pós-Graduação em Comunicação Social da Universidade Metodista de São Paulo: Tese de Doutorado, 2009.

BARBOSA, H. O jornalismo em concursos públicos. Disponível em: <http://sbpjor.kamotini.kinghost.net/ sbpjor/admjor/arquivos/individual47henriannebarbosa. pdf $>$. Acesso em: 7 jan. 2010.

BRASIL. Manual de redação: agência senado e jornal do senado. Brasília: Senado Federal, 2001. 
BOBBIO, N. O futuro da democracia. Rio de Janeiro: Paz e Terra, 1986.

BOBBIO, N. Teoria geral da política. Rio de Janeiro: Campus, 2000.

CALDAS, G. Comunicação pública e ciência cidadã. In: OLIVEIRA, M. J. da C. (org.). Comunicação pública. Campinas: Alínea, 2004. p. 29-47.

COLLINS, H; PINCH, T. Golem - O que você deveria saber sobre ciência. São Paulo: Unesp, 2003.

GOMES, W. Verdade e perspectiva: a questão da verdade e o fato jornalístico. Disponível em: <www.facom.ufba.br/ etica/txts/verdade.pdf >. Acesso em: 5 mai. 2005.

HABERMAS, J. Mudança estrutural da esfera pública. Rio de Janeiro: Tempo Brasileiro, 1984.

JUSTEN FILHO, M. Curso de direito administrativo. 2.ed. São Paulo: Saraiva, 2006.

LATOUR, B. A esperança de pandora. Bauru, SP: Edusc, 2001.

LAVALLE, Á. G. Espaços e vida públicos: reflexões teóricas sobre o pensamento brasileiro. São Paulo, 2001. Tese (Doutorado em Ciência Política) - Faculdade de Filosofia, Letras e Ciências Humanas, Universidade de São Paulo.

MARTINS, W. P. J. Transparência administrativa. São Paulo: Saraiva, 2004. 
PASQUALI, A. Um breve glossário descritivo sobre comunicação e informação. In:

PERELMAN, C.; OLBRECHTS-TYTECA, L. Tratado da argumentação: a nova retórica. 2.ed. São Paulo: Martins Fontes, 2005.

RANCIÈRE, J. O silogismo da corrupção. Disponível em: $<$ http://www1.folha.uol.com.br/fsp/mais/fs2210200013. htm>. Acesso em: 14 mai. 2007.

REBOUÇAS, E. Políticas públicas: os direitos à comunicação e o regime de propriedade intelectual. Disponível em: $<\mathrm{http}: / /$ www2.metodista.br/unesco/agora/PMC_Acervo_ eixos_focais_txt2_politicas_publicas.pdf $>$. Acesso em: jan. 2008.

REUTERS. Handbook of Journalism. Disponível em: $<$ http://handbook.reuters.com/handbookofjournalism. pdf $>$. Acesso em: 11 dez. 2009.

SCHUDSON, M. Por que a conversação não é a alma da democracia? In: MARTINS, F. M.; SILVA, J. M. da (Orgs.). A genealogia do virtual. Porto Alegre: Sulina, 2004. p.61-80.

WOLTON, D. Pensar a comunicação. Brasília: UnB, 1997. 


\section{Unidades noticiosas analisadas:}

\section{APROVADA Especialização em Educação}

Contextualizada. Disponível em: <http://www.insa.gov.br/ index.php?option=com_content\&task=view\&id=273\&Item $\mathrm{id}=100>$. Acesso em: 7 jan. 2010.

BOAS vindas a nova onça do MPEG. Disponível em: <http://www.museu-goeldi.br/sobre/ NOTICIAS/30_11_2009a.html> Acesso em: 7 jan. 2010.

3o CONGRESSO Brasileiro de Espectrometria de Massas. Disponível em: < http://www.lnls.br/lnls/cgi/cgilua.exe/ sys/start.htm?UserActiveTemplate $=$ lnls $\% 5 F 2007 \% 5 F$ portu gues\&infoid=2103\&sid=422> Acesso em: 7 jan. 2010.

CST/INPE participa de lançamento do relatório sobre dinâmica populacional e mudanças climáticas. Disponível em: <http://www.inpe.br/noticias/noticia.php?Cod_ Noticia=2049>. Acesso em: 7 jan. 2010.

CTI recebe Unidades de Pesquisa do MCT para Workshop em Saúde.

Disponível em: <http://www.cti.gov.br/index. php?option=com_content\&view=article\&id=253:cti-recebeunidades-de-pesquisa-do-mct-para-workshop-em-saude\&catid=75:noticias-\&Itemid=263>. Acesso em: 7 jan. 2010.

DIA Internacional de Segurança em Informática.

Disponível em: <http://www.on.br/conteudo/ noticias/2009/disi/disi.html>. Acesso em: 7 jan. 2010. 
DIRETOR do Cetene fala sobre tecnologias estratégicas em evento na Bahia. Disponível em: <http://www.cetene. gov.br/galerias/diretor-do-cetene-fala-sobre-tecnologiasestrategicas.php>. Acesso em: 7 jan. 2010.

I ENCONTRO Internacional do Sistema UAB debate desafios da Educação a Distância. Disponível em: <http:// www.rnp.br/noticias/2009/not-091125.html>. Acesso em: 7 jan. 2010.

ESPECIALISTAS discutem os Desafios e Perspectivas da Inclusão Digital na Sociedade da Informação. Disponível em: $<$ http://www.ibict.br/noticia.php?page $=0 \& i d=676>$. Acesso em: 7 jan. 2010.

FREITAS, Thatyana. Campus avançado do Cetem no estado do Piauí torna-se realidade. Disponível em: < http://www. cetem.gov.br>. Acesso em: 2 jan. 2010.

FREITAS, Thatyana. Cetem prepara lançamento do livro Fertilizantes: Agroindústria e Sustentabilidade. Disponível em: < http://www.cetem.gov.br>. Acesso em: 2 jan. 2010.

GILBERTO Câmara à frente do INPE por mais quatro anos. Disponível em: $<$ http://www.inpe.br/noticias/noticia. php?Cod_Noticia=2048>. Acesso em: 7 jan. 2010.

JORNADA maple começa dia $1^{\circ}$ no LNCC. Disponível em: $<$ http://www.lncc.br/frame.html>. Acesso em: 7 jan. 2010. 
JORDANO, D. Inpa discute importância da agricultura orgâanica. Disponível em: <http://www.inpa.gov.br/noticias/ noticia_sgno2.php?codigo=1406>. Acesso em: 7 jan. 2010.

LANÇADA nova chamada do edital para estimular implantação de repositórios institucionais. Disponível em: $<$ http://www.ibict.br/noticia.php?page $=0 \& i d=675>$. Acesso em: 7 jan. 2010.

LATINDisplay 2009/Projetos do CTI se destacam no evento. Disponível em: <http://www.cti.gov.br/index. php?option=com_content\&view $=$ article $\& i d=252$ :latindisp lay-2009-\&catid=75:noticias-\&Itemid=263>. Acesso em: 7 jan. 2010.

LIMA, Dayse. Morre, aos 95 anos, Marcello Damy, precursor da física nuclear no Brasil. Disponível em: <http://portal. cbpf.br/index.php? page=Noticias.VerNoticia\&id=311 $>$. Acesso em: 2 jan. 2010.

LNCC sedia encontro do INT. Disponível em: <http:// www.lncc.br/frame.html>. Acesso em: 7 jan. 2010.

LNLS contribui para nacionalização de tecnologia.

Disponível em: <http://www.lnls.br/lnls/cgi/cgilua.exe/ sys/start.htm? UserActiveTemplate=lnls\%5F2007\%5Fportu gues\&infoid=2102\&sid=422>. Acesso em: 7 jan. 2010.

MINISTRO da Cultura recebe propostas do Fórum da Cultura Digital Brasileira. Disponível em: <http://www.rnp. br/noticias/2009/not-091124a.html>. Acesso em: 7 jan. 2010. 
MORENO, T. Inpa recebe filhote de peixe-boi apreendido em coari. Disponível em: <http://www.inpa.gov.br/noticias/ noticia_sgno2.php?codigo=1407>. Acesso em: 7 jan. 2010.

OVÁRIO artificial permite produzir embriões em laboratório. Disponível em: <ttp://www.mct.gov.br/index.php/ content/view/314624.html>. Acesso em: 7 jan. 2010.

PASCUETO, C. Ciência às 6 e meia discute os rumos da astronomia frente aos avanços tecnológicos. Disponível em: $<$ http://portal.cbpf.br/index.php?page=Noticias. VerNoticia\&id=310>. Acesso em: 2 jan. 2010.

PESQUISADOR do Ipen ganha concurso científico de fotografia. Disponível em:

$<$ http://www.mct.gov.br/index.php/content/view/314621. html>. Acesso em: 7 jan. 2010.

PRESIDENTE Lula conhece a Biofábrica do Cetene. Disponível em:

Disponível em: <http://www.cetene.gov.br/galerias/lula_ visita_biofabrica.php>. Acesso em: 7 jan. 2010.

PROGRAMAÇÃO educativa do MPEG aborda as relações entre ciência e arte. Disponível em: < http://www.museugoeldi.br/sobre/NOTICIAS/30_11_2009b.html>. Acesso em: 7 jan. 2010. 
RAMOS, M. C. Curso capacita novos manejadores florestais. Disponível em: <http://www.mamiraua.org.br/noticias. php?cod=144\&tipo=noticia>. Acesso em: 7 jan. 2010.

REIS, M. et. al. Comunicadores populares se reúnem em encontro. Disponível em: <http://www.mamiraua.org.br/ noticias.php?cod=145\&tipo=noticia $>$. Acesso em: 7 jan. 2010.

SBPC: 62ª Reunião Anual é lançada em Natal. Disponível em: $<$ http://www.insa.gov.br/index.php?option=com_con tent\&task=view\&id=276\&Itemid=100>. Acesso em: 7 jan. 2010. 
